\title{
REAÇÕES DE MÃES DIANTE DO NASCIMENTO DE UM FILHO PREMATURO
}

[Reactions of mothers before a birth of premature son]

Tágira Márcia Teixeira Monteiro* Lucilane Maria Sales da Silva**

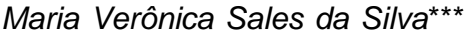

RESUMO: O nascimento de um filho prematuro é um acontecimento inesperado e estressante para os pais e, principalmente para as mães que, em geral, acompanham diretamente a criança. Apontando para uma atenção especial da equipe de saúde, no sentido de oferecer orientações e apoio necessário, objetivamos: identificar as reações de mães de crianças prematuras e verificar o preparo dispensado, pela equipe de saúde, às mesmas para lidar com a criança. Tratase de um estudo qualitativo, realizado no berçário da Santa Casa de Misericórdia de Sobral, com dez mães de crianças prematuras. Utilizamos para coleta de dados um roteiro de entrevista semi-estruturada, que foi aplicado no período de abril a maio de 2002. Consideramos os aspectos éticos conforme Resolução 196/96 relativo a pesquisas com seres humanos. Emergiram do estudo as seguintes categorias: reações da mãe ao nascimento do filho prematuro; o conhecimento sobre a prematuridade e o preparo para lidar com o filho prematuro. Acerca das reações das mães, foi possível inferir que as mães demonstram diversas reações tais como preocupação, medo e tristeza diante do nascimento do filho. As mesmas demonstraram desconhecer totalmente o assunto da prematuridade. A maioria das mães ignorava a possibilidade do filho nascer prematuro. O estudo destacou o despreparo das mães para lidar com a criança prematura e o desejo de obterem informações sobre o assunto. Sugere-se que a equipe de saúde ofereça apoio e orientações às mães e á família para que possam enfrentar e superar a situação.

PALAVRAS-CHAVE: Prematuridade; Reação das mães; Cuidados de enfermagem.

\footnotetext{
* Enfermeira assistencial da prefeitura municipal de Sobral.

** Enfermeira,Doutora em Enfermagem-UFC, Professora Adjunta da Universidade Estadual do Ceará

*** Enfermeira assistencial do município de Paracuru e Mestre em Enfermagem pela UFC.
}

\section{INTRODUÇÃO}

A notícia da chegada de um filho gera na família uma diversidade de sentimentos e emoções únicas. Antes mesmo de uma criança vir ao mundo, os pais têm com ela já inúmeras preocupações. Desejam que o ambiente, onde transcorrerá sua vida, seja o melhor possível, preparando-lhe o quarto para que seja agradável, alegre e bonito, tudo isto é realizado com imenso prazer, inclusive o enxoval.

Para BURROUGHS (1995) a gestação, envolvendo o parto, é talvez, a experiência mais emocionante e dramática na vida de uma mulher, sendo tremendo o impacto causado na mulher e em sua família.

Há situações em que a gestação é vivenciada sem o apoio da família e, muitas vezes, quando nasce uma criança com problemas, de prematuridade, a mãe é quem vivencia mais intensamente. Fato este verificado nas visitas a criança enquanto está no hospital, quando, em geral vemos a presença constante da mãe. A literatura médica e de enfermagem da atualidade reflete a experiência gestacional moderna: o foco ampliou-se dos aspectos puramente físicos para a visão psicossocial da gestação. Ela pode ser uma experiência excitante e gratificante, como pode também ser um período de estresse e mudanças abruptas na vida dos futuros pais, sendo, portanto, um desafio para a família.

Os pais, de uma maneira geral, procuram oferecer o melhor para o filho, preocupam-se, primordialmente, com sua saúde, mesmo antes do nascimento. Uma forma de cuidado para que a criança seja saudável, mesmo no período fetal é através da realização do pré-natal.

Todas as mães almejam que o nascimento de seu filho transcorra normalmente, no período esperado. Porém, em muitos casos e por diversas circunstâncias, uma criança nasce prematuramente, e este acontecimento abrupto pode gerar, não só na mãe, mas também na família uma atmosfera de incerteza e apreensão.

Historicamente, têm ocorrido importantes modificações na conceituação do recém-nascido prematuro. Segundo MORAIS e MARTINS FILHO (1997) a definição de prematuro 
baseado no peso ao nascimento, abaixo de 2.500 gramas, proposta pela Organização Mundial de Saúde em 1948, mostrou-se falha e de escassa confiabilidade, uma vez que se observam, neste grupo, crianças com indiscutível maturidade de seus órgãos e sistemas. Em vista disto, a partir dos anos 60, passou-se a definir como "recém-nascido de baixo peso" todo aquele com peso, ao nascimento, inferior a 2500 gramas, independentes da sua idade gestacional. Incluindo, neste grupo tanto recém-nascidos pré-termo como a termo, com retardo do crescimento intrauterino. "Recém-nascido pré-termo" passou a ser definido como toda criança nascida antes de 37 semanas de idade gestacional, tendo como base o primeiro dia do último período menstrual materno.

Autores como SEGRE (1991), consideram prematura toda criança nascida com 37 semanas completas de idade gestacional, mais precisamente, 37 semanas e 6 dias, ou seja, com menos de 38 semanas.

A prematuridade ou as condições a ela associadas constituem-se num dos problemas mais importantes do período neonatal. Trata-se de um problema não apenas de saúde, mas principalmente humano e social, pelas suas repercussões imediatas e a longo prazo.

Para REZENDE (1998) e SEGRE (1991), na grande maioria das vezes se desconhece o fator causador da prematuridade. Sabe-se que ela é responsável por aproximadamente $80 \%$ da mortalidade perinatal, e por $50 \%$ dos problemas neurológicos registrados atualmente.

Não é fácil determinar a incidência de parto prematuro, já que ocorre influência de vários fatores, tais como: população estudada, qualidade da assistência pré-natal, e até mesmo, da conceituação adotada para parto prematuro. Pois, existem divergências sobre a idade gestacional para classificar um recém-nascido como prematuro (REZENDE,1998).

O parto prematuro priva o neonato de obter as vantagens de uma completa vida intra-uterina. Sendo, portanto uma criança que necessita de assistência especial, já que o recém-nascido prematuro não tem o nível de maturação e a capacidade funcional dos órgãos para a vida extra-uterina, como o recém-nascido a termo.

A equipe de saúde encarregada da assistência ao recém-nascido prematuro efetuará cuidados gerais, especiais e intermediários para com o mesmo. $\mathrm{Na}$ assistência ao prematuro tanto o aspecto obstétrico quanto o pediátrico são revestidos da mais alta importância na luta contra a redução da mortalidade dessas crianças.

O nascimento de um bebê prematuro é um acontecimento inesperado e estressante para o qual os pais não estão emocionalmente preparados. Este estudo poderá fornecer fundamentações teóricas importantes para os profissionais que assistem crianças e famílias, na situação específica da prematuridade, através do seu desempenho, podendo melhorar a assistência materno-infantil.

Objetivamos com esse estudo identificar as reações psicológicas de mães de crianças prematuras e verificar o preparo dispensado, pela equipe de saúde, a mãe para lidar com a criança nascida prematuramente.

\section{METODOLOGIA}

Trata de um estudo de caráter descritivo e exploratório com uma abordagem qualitativa visando à identificação das reações psicológicas das mães diante do filho nascido prematuramente e o preparo destas para lidar com a situação. Foi realizado no Hospital Santa Casa de Misericórdia de Sobral (IMSCMS) - que atua como hospital de referência para a zona norte do estado do Ceará. O berçário da Santa Casa de Misericórdia de Sobral constituiu o cenário principal para a realização desse estudo, uma vez que os dados foram coletados durante a visita das mães ao seu filho. Inicialmente, tínhamos a intenção de trabalhar com os pais. Porém, verificamos que, na maioria das vezes, apenas as mães visitavam seus filhos, não sendo possível, portanto, abordar o pai no estudo.

Nos meses propostos para a coleta de dados, haviam registros na Maternidade da Santa Casa de Misericórdia de Sobral de 76 partos prematuros, dos quais 31 resultaram em recém-nascidos natimortos, e 45 de recém-nascidos prétermos que foram imediatamente conduzidos ao berçário para receberem a devida assistência.

Para o cumprimento dos objetivos desse estudo, solicitamos, inicialmente, autorização da instituição, mediante apresentação de um ofício explicativo da proposta do mesmo. Posteriormente, foram escolhidas aleatoriamente mães de crianças prematuras nascidas nos meses estabelecidos para a coleta de dados, para os quais foram esclarecidas sobre os objetivos desse estudo e convidadas a participarem do mesmo, mediante a apresentação do consentimento livreesclarecido, conforme exigência da Resolução 196, de 10 de outubro de 1996 (Diretrizes e Normas Reguladoras de Pesquisas envolvendo Seres Humanos) do Conselho Nacional de Saúde, que tem o mérito de dar ênfase aos compromissos éticos com os sujeitos da pesquisa, seja como indivíduo, ou coletividade. Esclarecemos, ainda, que as mães, nessa pesquisa, foram dentificadas na análise dos dados a partir de nomes bíblicos. A amostra desse estudo foi, então, constituída de 10 mães de crianças nascidas prematuramente, dentre aquelas que compareciam ao hospital para visitar ou acompanhar a evolução de seu filho. 
Para a coleta de dados foi utilizado a entrevista semiestruturada, com um formulário constituído por questões abertas e fechadas referentes ao objeto em estudo. Foi realizada nos meses de abril e maio de 2002, no período da manhã. Na coleta de dados, inicialmente, realizamos um teste piloto com cinco mães de crianças prematuras, no sentido de ajustar o formulário da entrevista.

Para a análise qualitativa dos dados não existe regra formal, no sentido estatístico, segundo CONTANDRIOPOULOS et al. (1999). No entanto, utilizamos, para análise dos dados, a análise de conteúdo que, para BARDIN (1979, p. 42), pode ser definida como "um conjunto de técnicas de análise de comunicação visando obter, por procedimentos sistemáticos e objetivos de descrição do conteúdo das mensagens, indicadores (qualitativos ou não) que permitam a interferência de conhecimentos de produção/recepção destas mensagens". Podemos concordar, ainda, com MINAYO (2000) quando relata que análise de conteúdo é a expressão mais comumente utilizada para representar uma pesquisa qualitativa. Sendo que o termo trata de uma busca teórica e prática no campo das investigações sociais e não somente um procedimento técnico.

\section{APRESENTANDO E ANALISANDO OS ACHADOS DOESTUDO}

\subsection{CARACTERIZAÇÃO DOS SUJEITOS DO ESTUDO}

Os sujeitos desse estudo, em sua totalidade, são constituídos de mães de recém-nascidos prematuros com idade variando de 17 a 39 anos, a maioria (08) possui o primeiro grau incompleto e apenas 02 o primeiro grau completo. 04 são casadas, 03 solteiras e 03 em união consensual. A renda variou de 01 a 02 salários mínimos e a maioria possui de 03 a 04 filhos.

\subsection{ANALISANDO AS CATEGORIAS ABSTRAÍDAS}

\subsubsection{Reações das mães ao nascimento prematuro do filho}

\section{Fiquei muito preocupada...}

Percebe-se que mais da metade das mães demonstram preocupação pela situação de prematuridade do filho por diversos motivos, entre eles, por estarem passando por um parto inesperado e pelo resultado deste evento, por este fato não ter ocorrido em gestações anteriores, sendo a primeira experiência e, principalmente, pelo futuro de seu filho. $\mathrm{O}$ que pode ser percebido nas seguintes falas:
Fiquei muito preocupada pois os meus outros quatro filhos nasceram normais e este não. Fiquei preocupada com a saúde do meu filho. (Rute)

Fiquei preocupada porque este é meu primeiro filho, e até quando eu vinha na ambulância para cá as dores estavam muito fortes e meu marido chorava muito comigo. (Rebeca)

Fiquei preocupada com que ia acontecer com meu filho, se ele ia viver e crescer normalzinho. (Sara)

Fiquei preocupada, não consegui dormir à noite. Eu pensei que fosse só eu, mas quando cheguei aqui vi que muitas pessoas passam por isso. (Ana)

O stress materno que ocorre em mães de crianças prematuras é resultado da experiência completamente diferente daquela que acontece em um nascimento a termo. No parto prematuro, em vez de um procedimento hospitalar rotineiro, há uma atmosfera de condições de emergência com uma apreensão geral sobre o destino da criança e, após o parto, a mãe tem uma preocupação aumentada sobre a normalidade de seu filho.

Observamos que as mães também demonstravam preocupação com o tempo de permanência do filho no berçário pois residindo em outras cidades, achavam inconveniente permanecer muito tempo longe de casa. Outras, por terem filhos menores, preocupavam-se ainda mais com a família.

Os profissionais de saúde devem auxiliar as mães e a família a enfrentar esta situação. De acordo com WHARLEY e WONG (1999) os pais de prematuros precisam saber que não estão sozinhos.

\section{Senti muito medo...}

Enquanto a maternidade representa uma satisfação para a mulher, o nascimento prematuro do filho tão sonhado ocasiona o medo do inesperado, do que poderia ocorrer com seu filho e do futuro agora incerto. Muitas mães relataram este sentimento:

Quando ele nasceu eu já estava passando mal, no oxigênio, eu achava que ele não ia sobreviver pois o choro dele foi muito fraquinho. Eu tinha tanto méd,o naquela hora. Eu já achava que tinha possibilidade da gente não sobreviver, tanto eu como ele. (Rebeca)

É doloroso. A gente tem medo de acontecer alguma coisa com o filho prematuro, de aparecer problemas mais graves no bebê. (Madalena)

Eu fiquei com medo porque as pessoas dizem que menino de sete meses não se cria, dizem que não fica normal como as crianças de nove meses, que há diferença. (Maria) 
Tive medo e ainda tenho até agora. Tenho medo dele não se criar, porque eu estou achando ele tão pequenininho. (Raquel)

Percebemos, nos relatos, que as mães do prematuro encaram o futuro com a expectativa do aparecimento de alguma anormalidade na criança, por conseqüência de seu nascimento prematuro.

Os pais de crianças prematuras sentem medo de que seu filho possa morrer e passam por um sofrimento prévio, mesmo sabendo que a criança está reagindo bem (ZIEGEL; CRANLEY, 1985).

Durante a investigação, observamos que algumas mães ficaram bastante emocionadas e choraram ao serem indagadas sobre o nascimento prematuro de seu filho.

\section{Senti uma tristeza profunda...}

Algumas mães relataram sentir tristeza por não terem tido o parto na época esperada e por não acreditarem na recuperação de seu filho prematuro. Segundo as falas:

Eu me senti triste porque este é meu primeiro filho e também, porque ele, sei lá, eu pensava que tinha condições de ter meu filho normalzinho. (Rebeca)

Quando me falaram que o "bichinho" era prematuro, eu fiquei muito triste, chorando. (Sara)

SILVA e MAMEDE (1998), definem a tristeza como um sentimento que provoca mudança na auto-estima do cliente, visto que esse sentimento é certamente originado de mágoas, insatisfações e desprazeres em relação à pessoa.

Ao nascimento de um filho, os pais devem elaborar a perda da criança idealizada, fantasiada e aceitar a criança real e quanto maior for a discrepância entre a realidade e a fantasia, mais difícil torna-se esta tarefa. Ao nascer uma criança sadia, o desapontamento em relação ao sexo e a aparência geral é prontamente superado, contudo, se for um filho prematuro a família passa por um período de tristeza profunda e permanece em crise por algum tempo (ZIEGEL; CRANLEY, 1985).

Os sentimentos de tristeza, que acometem algumas mães, foram manifestados durante a pesquisa através de atitudes como permanecer cabisbaixas durante a entrevista, aparentarem desolação, suspirarem durante a fala que, muitas vezes, era intercalada por momentos de pausa. Consideramos ser difícil para a mãe a visão da criança na incubadora, e a minúscula criança que a mãe vê, apenas aumenta seu sentimento de tristeza por ter tido um resultado desviado do que ela esperava.

\subsubsection{O Conhecimento sobre a prematuridade}

\section{Eu nunca ouvi falar disso...}

Quando indagadas acerca do conhecimento sobre prematuridade, as mães, de uma forma quase unânime, responderam desconhecer o assunto. Conforme as falas:

Não. Só me mandaram para cá. Ninguém me falou nada. Nenhum familiar meu teve prematuro. (Sara)

Não. De jeito nenhum eu ouvi alguma coisa. Lá na minha cidade eu não conheço ninguém que teve filho de sete meses eu sou a primeira. (Ana)

Não. Ainda não. Ninguém falou comigo sobre isso. (Madalena)

Nesse estudo, observamos que a maioria das mães sequer ouviu algum comentário acerca da possibilidade do filho nascer prematuro, sendo um acontecimento que para elas, jamais iria ocorrer. Apenas três mães afirmaram já terem ouvido alguém tecer comentários sobre a prematuridade. Sendo que o conteúdo desses comentários não fornecia informações claras e objetivas sobre o assunto. Os sujeitos transmissores dessas informações eram familiares ou vizinhos das mães em questão. Conforme as falas:

\section{Ouvi alguns comentários...}

Sim. Uma amiga minha teve um filho de sete meses e ele se criou. (Zípora)

Uma tia do meu marido falou que não era muita coisa. Que era ruim porque demorava muito no berçário. Que o bebê tem dificuldade para respirar, podia ele vingar, progredir, ou não ter possibilidade de viver. (Rebeca)

Sim. Só alguns comentários que a gente escuta das pessoas que tiveram filho de seis meses e que ele ficou um tempo na incubadora. (Léa)

\section{Eu queria tanto saber mais...}

As mães nessa pesquisa, quando indagadas sobre o recebimento de informações relativas a prematuridade, manifestaram o desejo, intenso em algumas ocasiões, de conhecerem o assunto. Elegendo corretamente, os profissionais da saúde, como os porta-vozes dessas informações. De acordo com as falas:

Eu gostaria de receber informações sobre o prematuro. Saber por que a gente tem o filho antes do tempo. Como a gente pega nele, os cuidados com o bebê. (Isabel) 
Eu não recebi nenhuma informação. Às vezes, a gente tem vontade de saber como é a criança prematura. Eu nunca tive criança antes do tempo. (Madalena)

Eu queria saber como pegar nele. As juntinhas dele são fracas, não é como na criança de nove meses. (Ana)

As pessoas dentro da área de saúde não vieram me informar. Eu tinha curiosidade de saber se um prematuro que vai para a incubadora sobrevive e sai uma criança normal e com saúde e se não traz nenhum problema. (Léa)

As famílias que têm um filho prematuro enfrentam uma crise durante o período de hospitalização da criança. Assim, a procura de informação pode ir acompanhada de raiva e piedade, seguindo-se de descrença e negação, segundo ZIEGEL \& CRANLEY (1985).

Os pais necessitam de orientação para estarem preparados para a nova experiência. Os profissionais de saúde devem acrescentar, o apoio psicológico aos pais, no seu plano assistencial, pois observamos através das falas das mães, desse estudo o interesse em aprender mais sobre o momento em que estão vivenciando. A intervenção de profissionais mais cuidadosos poderá ajudar a família a superar melhor a crise.

Para Kenner (2000), é necessário fornecer suporte à família durante toda a permanência do neonato no hospital. A transmissão de informações, juntamente com o apoio psicológico são papéis fundamentais dos profissionais de saúde que assistem mãe e criança.

\subsubsection{O preparo para lidar com o filho prematuro}

Quando indagamos às mães entrevistadas se elas sentiam-se preparadas para cuidar do seu filho ao retornarem ao lar e que tipo de preparação receberam, obtivemos as seguintes respostas:

\section{Vou cuidar como cuidei dos outros...}

Me sinto preparada porque já sou mãe. Vou cuidar como cuidei dos outros quatro filhos. (Raquel)

Estou, porque já cuidei dos outros. Com jeitinho, a gente cuida. (Ana)

De acordo com as falas, percebe-se a aceitação das mães para cuidar dos filhos prematuros, inclusive, da mesma forma com que cuidaram dos filhos anteriores, ou seja, tiveram como suporte o fato de já serem mães de outras crianças. Essas mães nos remetem a afirmação do que é ser mãe, este sentimento tão sublime. Podemos observar que as mães nessas falas apesar de passarem por um fato estressante, evidenciam o amor materno capaz de superar todos os obstáculos por elas enfrentados.

Uma mãe afirmou sentir-se preparada por ter recebido informações de como cuidar de seu filho. Vejamos na fala dessa mãe:

Estou. As enfermeiras falaram que eu devo amamentar na hora que ela quisesse. Não devo dar comida. Ter cuidado com as coisinhas dela. (Rute)

A estimulação do aleitamento materno é um dos assuntos mais estudados pela enfermagem. De acordo com o Ministério da Saúde (BRASIL, 1997) o leite materno é o alimento ideal para o bebê. Ele fornece para a criança propriedades nutricionais, psicológicas e de defesa contra infecções. Sendo portanto, fundamental para a saúde e o desenvolvimento da criança, além de trazer importantes vantagens para a mãe.

Enquanto que algumas mães se sentiam devidamente preparadas para cuidar de seu filho prematuro, as demais afirmaram não estarem preparadas, manifestando também o desejo de receberem detalhes acerca do assunto. Conforme as falas:

\section{Eu quero que alguém me ensine...}

Não. Eu tenho medo porque é meu primeiro filho e ainda nasceu antes do tempo. Eu queria saber como cuidar dele. Às vezes fica mais difícil de pegar nele por ele ser tão pequenininho e molinho. (Isabel)

Não. Eu não sei como cuidar porque ele é prematuro. Apesar de não ser eu que vou cuidar dele, é minha mãe, eu queria saber como é que cuida. (Maria)

Não. Eu estava até querendo saber. As meninas me falaram que é um bebê que precisa de cuidados especiais. Porém não sei como cuidar dele em casa, já que ele é mais frágil. (Zípora)

Percebe-se que estas mães manifestaram o desejo de conhecer os cuidados que devem ter com os filhos prematuros no regresso ao lar. As demais mães restantes, além de expressar este desejo, demonstraram que queriam que os profissionais de saúde desempenhassem o papel de esclarecedores desses assuntos. Vejamos isso nas falas:

Não. Eu não sei lidar com criança prematura. Na alimentação vai ser diferente. Vai ser diferente em tudo. Tenho dúvida sobre a saúde, como cuidar. Porque ele é mais especial. O estômago, o intestino é pequeno. Por mim eu queria ter uma pessoa que seja especialista naquilo, tipo uma enfermeira. Pois eu iria ficar mais tranqüila, porque sei que a pessoa iria saber direitinho. (Léa) 
Não. Eu tenho uma pequena idéia. Muita gente fala que é para ter contato com um profissional de saúde. Se fosse possível eu queria ter uma enfermeira em casa para me ensinar a cuidar do prematuro. Ou então receber informações de quinze em quinze dias. (Rebeca).

Notamos que essas mães manifestaram o desejo intenso de terem algum profissional de saúde por perto auxiliálas e cuidar de seu filho prematuro. Constatamos a confiança e respeito atribuídas aos profissionais de enfermagem demonstradas por estas mães. Pois seriam destes profissionais que as mães obteriam as informações necessárias para cuidar de seu filho ou então, entregariam-o para prestar cuidados.

Para WHARLEY e WONG (1999), à medida que se aproxima a alta do filho, os pais ficam muito apreensivos e exaltados. Eles têm muitas preocupações e insegurança no que se refere aos cuidados com o bebê. Eles temem que a criança ainda possa estar correndo perigo e que não conseguirão reconhecer os sinais de sofrimento ou doença no seu bebê. A enfermagem precisa começar cedo a ajudar os pais a adquirir ou aumentar as habilidades nos cuidados do seu bebê. Deve-se instruir apropriadamente os pais e permitir tempo suficiente para a família assimilar as informações e aprender a reconhecer as necessidades básicas dos cuidados especiais.

A enfermeira de saúde pública é importante na transição do hospital para o lar, já que ela deve visitar o bebê depois que este vai para casa, a fim de prestar assistência adicional nos cuidados com o recém-nascido (ZIEGEL e CRANLEY, 1985).

\section{Se Deus quiser tudo vai dar certo...}

Não estou preparada. Mas seja o que Deus quiser. Eu nunca havia visto um bebê prematuro. Fiquei surpresa com o tamanho. Tenho fé em Deus que minha filha vai se criar sadia. Deus sabe o que faz. (Madalena)

Se Deus quiser. Eu quero cuidar dele com a ajuda de Deus. Eu acho que devo tratar ele bem, mais do que o meu primeiro filho, que nasceu de nove meses. (Sara)

Percebemos que duas mães manifestaram sentimentos ambíguos. Não se consideravam totalmente preparadas para cuidar de seu filho prematuro, entretanto, tinham a religiosidade como um porto seguro, do qual retiraram as forças para seguir em frente e vencer o receio em cuidar de seu filho tão sensível.

A religiosidade, a confiança plena em um ser supremo capaz de realizar coisas inacreditáveis, é manifestada nessas mães que relataram desconhecer o fato pelo qual estavam passando, mas contavam com a ajuda de Deus para enfrentarem essas situações e demonstravam-se confiantes no bom resultado desse problema.

\section{CONSIDERAÇÕES FINAIS}

Os achados do estudo nos permitiram concluir que, as mães participantes da pesquisa, tiveram as mais variadas reações ao nascimento prematuro do filho. O medo foi um elemento significativo sendo relatado por diversas mães. Medo por enfrentarem um parto prematuro, pois temiam as possíveis conseqüências deste evento e temiam pela saúde do filho. A preocupação com o bem-estar do filho, um ser que na visão das mães pesquisadas, transmitia fragilidade ou então um aspecto senil. A tristeza por estarem numa situação diferente das mães que tiveram seus filhos a termo e podem, a todo o momento, acariciá-lo, amamentálo, envolvê-lo em seus braços.

Devido à ausência de informações sobre a prematuridade, algumas mães afirmaram serem completamente leigas no assunto. Outras relataram já terem escutado alguns comentários, entretanto, nada que informasse claramente sobre a situação que estavam vivenciando. Muitas mães, além de afirmarem desconhecer o assunto manifestaram o desejo de obter informações detalhadas sobre prematuridade.

Constatamos que cinco das mães ignoravam a possibilidade de nascimento prematuro do filho, fosse pelas gestações anteriores ou por terem uma gestação tranqüila. Enquanto que as demais mães entrevistadas afirmaram saberem que seu filho poderia nascer prematuro tendo como motivo as intercorrências ocorridas durante a gravidez.

Quando indagadas da preparação para cuidar dos filhos prematuros no retorno ao lar, obtivemos três respostas a esta pergunta: algumas mães sentiam-se preparadas por já serem cuidadoras dos filhos anteriores, achando-se portanto, experientes para cuidar dos filhos; outras sentiam-se despreparadas mais iriam enfrentar a situação tendo como aparato psicológico a religiosidade. Finalmente, as mães restantes que se intitulavam despreparadas mas, exigiam o devido preparo fornecido por um profissional de saúde, preferencialmente a enfermagem.

O estudo revelou o desamparo e despreparo das mães no que diz respeito a transmissão de informações sobre prematuridade, a preparação para assumirem o papel de cuidadoras dos filhos prematuros no lar e principalmente, ao apoio psicológico para enfrentarem com segurança o momento difícil no qual estão vivenciando. 
Diante do exposto podemos observar que os profissionais de saúde se encontram enfatizando o modelo biomédico, no qual interessam-se apenas pelos aspectos clínicos do paciente, esquecendo de abordar o paciente dentro de uma visão holística, distanciando-se de um conceito de saúde mais abrangente.

Sugere-se que esses profissionais, em especial, dêem ênfase aos aspectos psicológicos dos pacientes a quem prestam assistência, elaborando um plano assistencial que englobe todas as necessidades do indivíduo, visando atender plenamente o cliente e família.

ABSTRACT: The birth of a premature son is something unexpected and stressful for all the families and mainly for the mother, that generally, follow directly the child. Pointing for a special attention of the health team has as objectives to identify the reactions of mothers of premature children and verify the dispensed background, by health team, to mothers to take care of a child. It is a qualitative study done at Santa Casa de Misericórdia nursery in Sobral, with the ten mothers in a period from April to May of 2002. We considered ethical aspects according to resolution 196/96 related to researches with human beings. The following categories appeared from the study: mothers' reactions to the birth of a premature son; the knowledge about the premature son. With respect to the psychological reactions of the mothers, it was possible to infer that mothers show several reactions such as concern, fear and sadness when their sons are born. These mothers show that they don't know anything about the matter of prematurity. The majority of mother ignored the possibility of the son to be born premature. The study emphasized the unpreparedness of the mothers to take care of a premature child and their desire to obtain information about the matter. It is suggested that the health team offers support and guidance to the mothers and family. In this way they can face and overcome the situation.

KEY-WORDS: Premature; Mothers reations; Nursing care.

\section{REFERÊNCIAS}

1 BARDIN, L. Análise de conteúdo. Lisboa: Edições 70, 1979. 123p.

2 BRASIL. Conselho Nacional de Saúde. Resolução N. 196/96. Decreto $\mathrm{N} .^{\circ} 93.9333$ de janeiro de 1987. Estabelece critérios sobre pesquisa envolvendo seres humanos. Bioética, v. 4, n. 2, supl. 1996. $68 p$.

3 BRASIL. Ministério da Saúde. Assistência pré-natal: Manual técnico. 3.ed. Brasília, DF: MS, 2000.

4 BRASIL. Ministério da Saúde. Manual de promoção do aleitamento materno: normas técnicas. 2.ed. Brasília, 1997.

5 BURROUGHS, A. Uma introdução à enfermagem materna. 6.ed. Porto Alegre: Artes Médicas, 1995. 456p.

6 CONTANDRIOPOULOUS, A. P., et al. Saber preparer uma pesquisa: definição, estrutura, financiamento. 3. ed. Rio de Janeiro: Hucitec Abrasco, 1999.

7 KENNER, C. Enfermagem neonatal. 2. ed. Rio de Janeiro: Reichman A. Affonso, 2001.

8 MINAYO, M. C. Souza. O desafio do conhecimento: pesquisa qualitativa em saúde. 7. ed. Rio de Janeiro, 2000.

9 MORAIS, E. N; FILHO, F. M. Medicina materna e perinatal. 6. ed. São Paulo: Revinter, 1997.

10 REZENDE, J.; MONTENEGRO, C. A. B. Obstetrícia. 7. ed. Rio de Janeiro: Guanabara Koogan, 1998.

11 REZENDE, J.; MONTENEGRO, C. A. B. Obstetrícia fundamental. 8.ed. Rio de Janeiro: Guanabara Koogan, 1998.

12 SEGRE, C. A. M et al. RN. 3.ed. São Paulo: Sarvier, 1991. 678p.

13 SILVA, R. M.; MAMEDE, M. V. Conviver com a mastectomia. Fortaleza: UFC, 1998.

14 WARLEY, L. F; WONG, D. L. Enfermagem pediátrica: elementos essenciais à introdução efetiva. 5.ed. Rio de Janeiro: Guanabara Koogan, 1999.

15 ZIEGEL, E. G.; CRANLEY, M. Enfermagem obstétrica. 8.ed. Rio de Janeiro: Guanabara, 1985.
Endereço das autoras: Rua Gustavo Braga, 257 60430-120 - Fortaleza - CE E-mail: versalles57@hotmail.com 